\title{
Sperm-oocyte interplay: an overview of spermatozoon's role in oocyte activation and current perspectives in diagnosis and fertility treatment
}

\author{
Mohammad Ishraq $\operatorname{Zafar}^{1} \mathbb{D}$, Shi $\mathrm{Lu}^{2}$ and Honggang $\mathrm{Li}^{1,3^{*}}$
}

\begin{abstract}
The fertilizing spermatozoon is a highly specialized cell that selects from millions along the female tract until the oocyte. The paternal components influence the oocyte activation during fertilization and are fundamental for normal embryo development; however, the sperm-oocyte interplay is in a continuous debate. This review aims to analyze the available scientific information related to the role of the male gamete in the oocyte activation during fertilization, the process of the interaction of sperm factors with oocyte machinery, and the implications of any alterations in this interplay, as well as the advances and limitations of the reproductive techniques and diagnostic tests. At present,

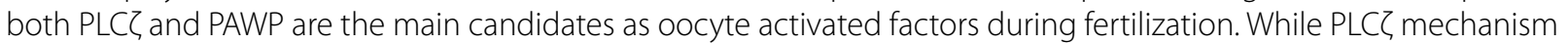
is via $\mathrm{IP}_{3}$, how PAWP activates the oocyte still no clear, and these findings are important to study and treat fertilization failure due to oocyte activation, especially when one of the causes is the deficiency of PLC $\zeta$ in the sperm. However, no diagnostic test has been developed to establish the amount of PLC , the protocol to treat this type of pathologies is broad, including treatment with ionophores, sperm selection improvement, and microinjection with PLCद protein or RNA.
\end{abstract}

Keywords: Oocyte activation, Calcium oscillations, Sperm oocyte activation factors (SOAF), Male infertility diagnosis, Artificial oocyte activators (AOAs), Male infertility, Male infertility treatment

\section{Background}

In animals, gamete identification and other findings showing that the spermatozoon enters the oocyte to form the embryo, leading to new hypotheses and experiments for discovering the mechanisms of the fertilization process.

In mammals, fertilization involves a series of consecutive steps that starts with the recognition and fusion of sperm and oocyte membranes. This event triggers a

\footnotetext{
*Correspondence: Ihgyx@hotmail.com

${ }^{1}$ Institute of Reproductive Health/Center of Reproductive Medicine,

Tongji Medical College, Huazhong University of Science and Technology,

13 Hang Kong Road, Wuhan 430030, People's Republic of China

Full list of author information is available at the end of the article
}

pathway that induces persistent cytosolic calcium $\left(\mathrm{Ca}^{+2}\right)$ oscillations, which are necessary and sufficient to stimulate embryo development [1]. The $\mathrm{Ca}^{+2}$ oscillations last for several hours $[2,3]$, are the common signal of oocyte activation, and start the intricate embryonic development process to form a zygote.

It was believed that the spermatozoon's only contribution to the embryo formation was its genome. In recent times, extensive studies have shown that the spermatozoon contribution is substantial; it contributes both its DNA and its entire structure to embryo formation [4]. Upon fertilization, sperm-specific proteins and factors trigger $\mathrm{Ca}^{+2}$ oscillations to activate the oocyte. While the sperm centriole guides both oocyte and sperm nuclei to form the zygote nucleus 
and sperm DNA structures, chromatin and free RNAs can be modified to activate/deactivate gene expression involved in embryo development [5]. These interactions demonstrate that the spermatozoon has an active role in both oocyte activation and zygote formation, affecting the embryo's phenotype directly.

Since 2002, numerous studies have shown that the sperm oocyte-activator factor (SOAF), phospholipase C zeta (PLC $\zeta$, is involved in oocyte activation, promoting MII resumption and pronuclear formation through the inositol-1,4,5-triphosphate $\left(\mathrm{IP}_{3}\right)$ pathway. In 2007 the PAWP protein was proposed to be a SOAF [6]. The role and importance of each protein, and the pathway for oocyte activation, are new topics of debate among investigators worldwide. One goal is to identify specific receptors within the oocyte that interact with these factors, triggering $\mathrm{Ca}^{+2}$ oscillations and oocyte activation upon fertilization.

Advances in reproductive biotechnological medicine have helped to clarify our understanding of the stages of fertilization and embryo development. At present, intracytoplasmic sperm injection (ICSI) is widely used in assisted reproductive technology (ART). The aim of ART is to achieve fertilization by directly injecting the sperm into the oocyte by passing the many biological barriers in the process [7]. Continuous improvement in ART has allowed severe infertility cases to be successful, even when recurrent fertilization failures occur after conventional in vitro fertilization (IVF).

The total fertilization failure (TFF) is when all the oocytes collected within one cycle of stimulation fail to form pronuclei, with oocyte activation deficiency $(\mathrm{OAD})$ as the primary cause of such failures [8]. It has been demonstrated that PLC $\zeta$ protein absence in the sperm head is associated with direct failure to signal $\mathrm{Ca}^{+2}$ oscillations [8]. While ICSI has a high rate of success, there are still cases of OAD involving ICSI failure. Pharmaceutical alternatives to activate the oocyte artificially are $\mathrm{Ca}^{+2}$ ionophores, known as artificial oocyte activators (AOAs). Modifications of reproductive technologies such as intracytoplasmic sperm injection followed by microinjections of mRNA PLC $\zeta$ and recombinant active PLCל protein [9] have been developed for cases where AOAs have failed. Therefore, it has been suggested that PLC could be a fundamental clinical diagnosis biomarker [10]. However, there is a need to establish diagnostic protocols and reference clinical ranges to apply this treatment to infertile patients.

The aim of this review is to select and discuss reports that elucidate the importance of the spermatozoon in fertilization and its active role in mammalian oocyte activation. We intend to clarify the complex mechanism of oocyte activation and propose new ART strategies that can be applied in human reproductive pathologies.

\section{From membrane fusion to oocyte activation}

Upon fertilization, a signaling pathway induces the cortical granules in the ooplasm (the oocyte cytoplasm) to fuse with the oocyte membrane and release their contents into the extracellular matrix (Fig. 1-normal activation). This phenomenon, known as the cortical reaction, is associated with another event called the zona reaction, which is the modification of the structure of the zona pellucida to block polyspermy and protect the developing embryo during implantation. What triggers this sequence of events remains unknown.

Since the establishment of Loeb's principle, which states that the spermatozoon has major roles in fertilization, promotion of cell division and paternal inherence to the offspring, a series of studies and discussions have taken place within the scientific community [11]. At present, the second role of the spermatozoon, as per Loeb, is fundamental to initiating oocyte activation, a complex series of events that involve both the sperm and oocyte factors.

Once the oocyte recognizes the spermatozoa, the sperm binds the zona pellucida protein ZP-3, which functions as a sperm recognition receptor. The acrosomal membrane surrounding the spermatozoon head (Figs. 1-normal activation and 2) reacts and fuses with the oocyte membrane in a phenomenon called the acrosome reaction. A sperm membrane protein, Izumo1, binds to its counterpart Juno, an oocyte receptor, and trigger the membrane fusion of the two gametes. This interaction has been identified as essential and extremely regulated and is the culmination of the fertilization process [12]. The fusion of the gametes' membrane allows sperm factor entry. These events trigger a signaling pathway in the ooplasm that releases intracellular calcium $\left(\mathrm{Ca}^{+2}\right)$, leading to the exocytosis of cortical granules to the extracellular matrix followed by pronuclei formation, maternal mRNA recruitment, and release from meiotic arrest. This series of events leads to forming a single activated cell, the zygote, and initiation of embryonic gene expression.

In mammals, fluorescent $\mathrm{Ca}^{+2}$ sensitive dye techniques help confirm that sperm entry causes persistent oscillations of intracellular $\mathrm{Ca}^{+2}$ in the ooplasm [13]. The release of $\mathrm{Ca}^{+2}$ is the common signal of oocyte activation [14].

\section{$\mathrm{Ca}^{+2}$ signaling}

Since the 1970s, it has been believed that an increase in the levels of intracellular $\mathrm{Ca}^{+2}$ in the ooplasm during fertilization is a fundamental signal for the fertilization 


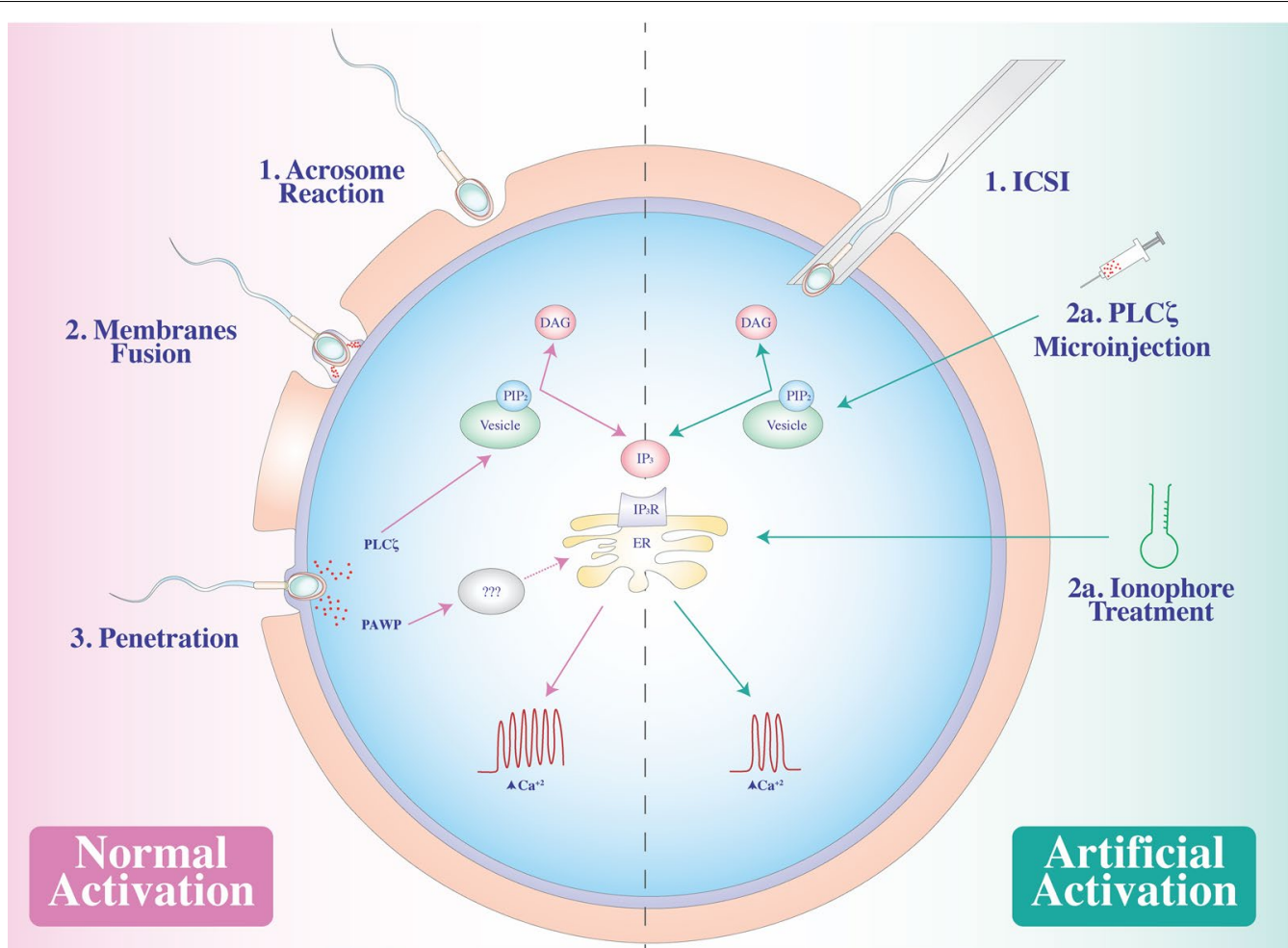

Fig. 1 The role of the sperm factors in the oocyte activation. In the normal activation process, the acrosome reaction (1) allows the exposure of PT for the fusion of the sperm membrane with the oocyte (2), starting in the equatorial segment and continuing to the PAS-PT, until penetration (3). SOAF are released into the ooplasm and triggers the $\mathrm{Ca}^{+2}$ oscillations via IP ${ }_{3}$. In the artificial oocyte activation, different strategies following ICSI could trigger $\mathrm{Ca}^{+2}$ oscillations, PLCद microinjections (2a) or ionophore treatments (2b)

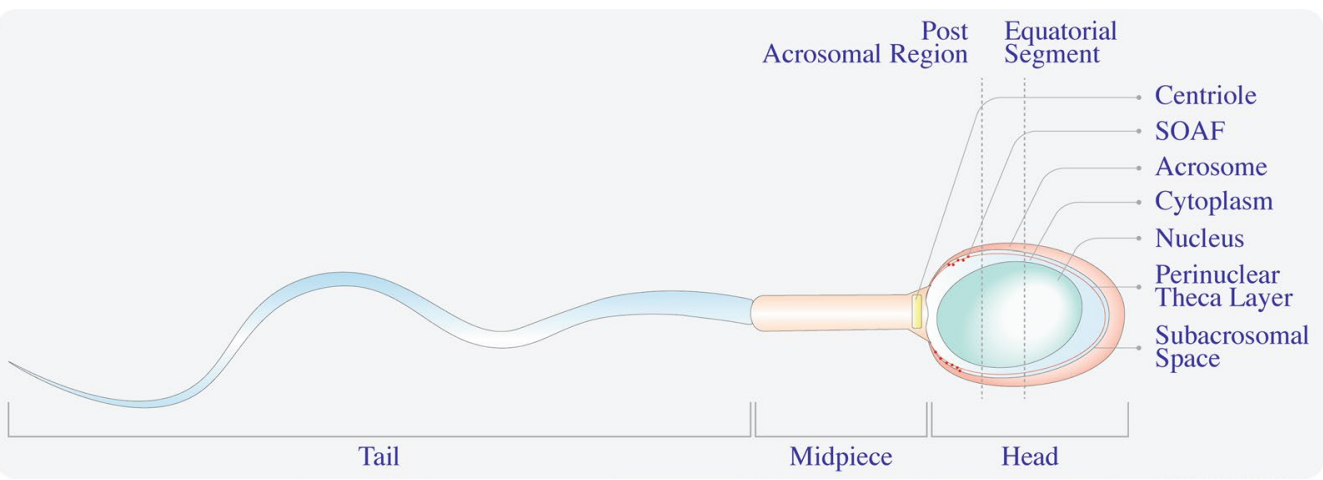

Fig. 2 Spermatozoon acrosomal organization. The spermatozoon has three fundamental pieces: tail, middle, and head. The sperm head has a prominent and compact nucleus, surrounded by a thin cytoplasm that contains nuclear vesicles. The PT is a thin protein layer underneath the acrosomal membrane and is divided into a subacrosomal region, equatorial segment, and PAS-PT. The PAS-PT contains SOAF and is the first to be exposed in the ooplasm during fertilization

process to succeed. Studies in mammals have shown that intracellular $\mathrm{Ca}^{+2}$ is stored in the endoplasmic reticulum (ER) and mobilizes to the ooplasm in spatial-temporal waves. $\mathrm{Ca}^{+2}$-sensitive fluorescent dye techniques have established $\mathrm{Ca}^{+2}$ and oscillation patterns in mammals, including pigs, rats, cows, mice, and humans. The frequency and amplitude of $\mathrm{Ca}^{+2}$ release patterns are crucial for oocyte activation and the preliminary stages of embryogenesis to occur, thereby are distinctive of each species. For example, a low frequency with one $\mathrm{Ca}^{+2}$ 
spike occurring every 10 minutes was observed in mouse oocytes, while in humans, pigs, and cows, each $\mathrm{Ca}^{+2}$ spike occurred once every 30 to $60 \mathrm{~min}[13,15]$.

In mammalian fertilization, the rise of intracellular $\mathrm{Ca}^{+2}$ depends on the activation of inositol-1,4,5-triphosphate receptors $\left(\mathrm{IP}_{3} \mathrm{R}\right)$ located in specialized compartments of the ER membrane [14, 16, 17] (Fig. 1-normal activation). This process is known as $\mathrm{Ca}^{+2}$-induced $\mathrm{Ca}^{+2}$ release (CICR process) and is based on two types of $\mathrm{Ca}^{+2}$ channels: $I P_{3} \mathrm{R}$ and ryanodine receptors (RYR). Both types of channels are $\mathrm{Ca}^{+2}$-depending for stimulation and inhibition, so during the process, these channels open and close in order the discharged $\mathrm{Ca}^{+2}$ from the internal ER store, the rise of cytoplasmic $\mathrm{Ca}^{+2}$ inactivates the receptors, and the $\mathrm{Ca}^{+2}$ is driven back to the store, the cytoplasmic concentration returns to the basal status, and the cycles starts again. Although this mechanism is not fully understood, it is known that the penetration of the spermatozoon triggers the CRIC process [18].

Regulating these $\mathrm{IP}_{3}$ signaling pathways in the oocyte is phospholipase C (PLC). This cytosolic enzyme catalyzes the hydrolysis of phosphatidylinositol 4,5-biphosphate $\left(\mathrm{PIP}_{2}\right)$ in $\mathrm{IP}_{3}$ and diacylglycerol (DAG). Store-operated calcium entry, involving a group of molecules including STIMI, ORAII, and SERCA, plays a key role in $\mathrm{Ca}^{+2}$ homeostasis. This mechanism allows the refill of the ER with free $\mathrm{Ca}^{+2}$ and generation of $\mathrm{Ca}^{+2}$ oscillations that are observed in oocyte activation [19]. Although the fully $\mathrm{Ca}^{+2}$ oscillations mechanism, and its relationship with the completion of meiosis, are unknown, its involve other proteins, like calmodulin-dependent protein kinase II (CAMK-II), cyclin, and cohesin, which hold the chromosomes together, and the inactivation of the mitogenactivated protein (MAP)-kinase, involve in the increase of DNA synthesis. All these are critical for the downstream signaling cascade modulated by $\mathrm{Ca}^{+2}$ release [2, $18,19]$. It has been demonstrated that the specific frequency of $\mathrm{Ca}^{+2}$ spikes can affect oocyte activation and early embryo development, resulting in fewer pregnancies [20]. The reason for this is the need for two constant and simultaneous active stimuli: cyclin B synthesis and cyclin-dependent kinase 1 (CDK1). Cyclin B maintains CDK1 activity, while CDK1 holds the oocyte in meiotic arrest. A spike in intracellular $\mathrm{Ca}^{+2}$ levels increases cyclin B's proteolysis, reducing CDK1 activity and causing the resumption of oocyte meiosis [21]. However, if only one spike in intracellular $\mathrm{Ca}^{+2}$ levels occurs, cyclin B restores its synthesis, CDK1 increases its activity, and the oocyte is re-arrested [21, 22].

The secretions of metabolic enzymes, gene expressions, among other molecular and cellular functions, are related to the intracellular $\mathrm{Ca}^{+2}$ rise. So, $\mathrm{Ca}^{+2}$ plays the second messenger role and is responsible for releasing the oocytes from the meiotic arrest and triggered the embryonic development program [23].

Different theories involving intracellular $\mathrm{Ca}^{+2}$ oscillations during fertilization have been introduced, including the injection of $\mathrm{Ca}^{+2}$ in the ooplasm by a sperm membrane $\mathrm{Ca}^{+2}$ bomb or channel [24] and the sperm oocyte interaction hypothesis [25], in which an interaction between a sperm ligand and an oocyte receptor triggers $\mathrm{Ca}^{+2}$ oscillation. Although the exact mechanism of intracellular $\mathrm{Ca}^{+2}$ release is not clear, a consensus for SOAF triggering the release of intracellular $\mathrm{Ca}^{+2}$ upon fertilization exists, as well as the participation of other agents, such as cyclic GMP (cGMP), cyclic ADP-ribose (cADP ribose), nicotinic acid adenine dinucleotide phosphate (NADP) and nitric oxide (NO) in the rise of intracellular $\mathrm{Ca}^{+2}[19]$.

\section{Sperm oocyte-activating factors}

The development of new biotechnological tools that can be applied in diagnosis and clinical research, such as $\mathrm{Ca}^{+2}$ imaging and ICSI, has led to the dismissal of the hypotheses of the $\mathrm{Ca}^{+2}$ bomb or ligand-receptor mechanisms. Although both theories explain intracellular $\mathrm{Ca}^{+2}$ increase, both failed in explaining how $\mathrm{Ca}^{+2}$ oscillations persist over time [20, 26, 27]. In contrast, the "sperm factor" theory, according to which oocyte activation is triggered by a soluble sperm factor released into the oocyte, was rapidly accepted.

Since Loeb's principle in 1913, evidence about sperm ability to activate oocyte has been increasing and has been proposed several "sperm factors" (Fig. 3). Swann et al. provided the first reported evidence for this sperm factor [28] by injecting a sperm cytosolic extract into the oocyte and observing $\mathrm{Ca}^{+2}$ oscillations, like those observed during fertilization. This factor remained unidentified for several years before indirect evidence in literature helped define it.

The SOAF must possess the following specific characteristics and functions: it should be capable of triggering persistent oscillations of intracellular $\mathrm{Ca}^{+2}$ from ooplasmic resources in a manner indistinguishable from mammalian fertilization. This mechanism should involve the increased production of $\mathrm{IP}_{3}$, regulated by the phosphoinositide-signaling pathway.

Location was also important for the SOAF function (Fig. 2). The sperm head has a region called the perinuclear theca (PT), a condensed cytosolic protein layer that surrounds the nucleus and can be divided into structural or functional zones [29]. The functional zones are divided into three further parts: a subacrosomal region, equatorial segment, and postacrosomal sheath-perinuclear theca (PAS-PT). The PT contains proteins that maintain the sperm head's structure and coat the nucleus (Fig. 2). 


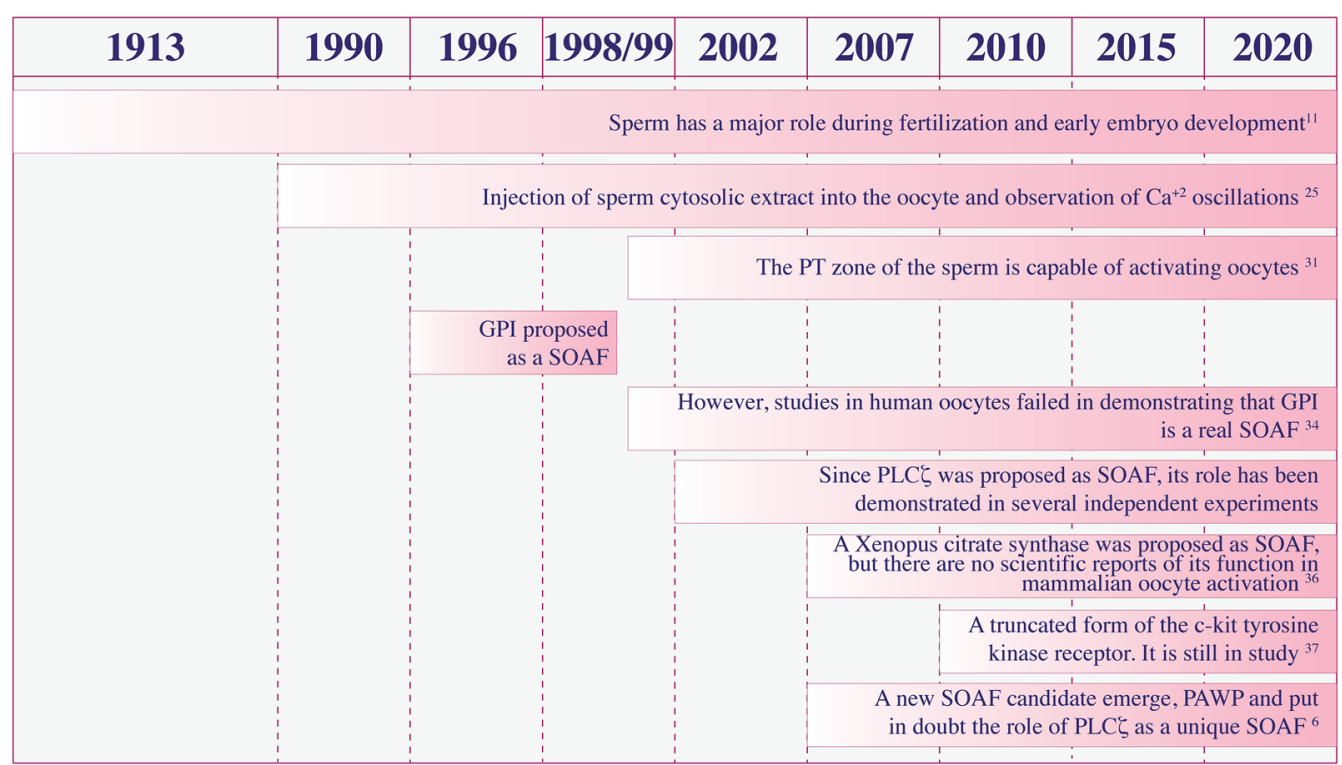

Fig. 3 A History of SOAF candidates. A timeline with the most important reports about the role of the sperm factor candidates in the oocyte activation mechanism

When fertilization begins, the sperm's fusion with the oocyte begins in the equatorial segment and continues to the PAS-PT, thus this last region being the first that is exposed to the ooplasm. Experiments assessing the regions of the sperm capable of activating oocytes, involved an injection of the head or tail of a spermatozoon into mouse oocytes [30], indicating that only the sperm head can activate the oocyte. Moreover, when sperm heads were treated with substances that alter all membranes, such as proteases or detergents that denaturalize proteins, sperm failed to activate the oocytes. Meanwhile, when treated with Triton X-100, a non-ionic surfactant that removes all membranes except the PT around the nucleus, the sperm retains the ability for activation [31]. Data show that SOAF could be a protein [28, 32]; however, most of the proteins investigated did not match the physiological characteristics expected of an oocyte activator factor.

The first candidate was a glucosamine-6-phosphate isomerase (GPI), a deaminase homologue to the hamster oscillin, and a putative soluble protein associated with $\mathrm{Ca}^{+2}$ oscillation-inducing activity in mammalian oocytes, located in the equatorial segment of the sperm head [33]. However, injection of hamster oscillin did not induce $\mathrm{Ca}^{+2}$ oscillations in mouse oocytes [34]. Likewise, a recombinant form of the human GPI also did not induce $\mathrm{Ca}^{+2}$ oscillations [35]. Immunodepletion of GPI from sperm extracts failed to block $\mathrm{Ca}^{+2}$ oscillations [35].

Another SOAF candidate considered was a homolog of Xenopus citrate synthase. This $45-\mathrm{kDa}$ protein was controversial; it triggered $\mathrm{Ca}^{+2}$ oscillations in unfertilized newt oocytes, and treatment with anti-citrate synthase antibody in sperm extracts reduced oocyte activation. There are no scientific reports of its function in mammalian oocyte activation or in the fertilization process [36].

A truncated version of the c-kit tyrosine kinase receptor, Tr-Kit, was another SOAF candidate. Although this receptor's role in mammalian fertilization is still unknown, it is expressed in the equatorial region of the sperm head and persists after the acrosome reaction in high-quality sperm $[37,38]$.

Sperm extract that triggers $\mathrm{Ca}^{+2}$ oscillations contains higher PLC activity, and this stimulation can be differentiated from oocyte PLC activity [39]. As the PLC family of proteins has a critical function in the oocyte activation cascade, they became a major focus of clinical research $[14,40]$. These proteins catalyze the hydrolysis of $\mathrm{PIP}_{2}$, generating $\mathrm{IP}_{3}$ and DAG, allowing $\mathrm{IP}_{3}$ to bind its receptor and release intracellular $\mathrm{Ca}^{+2}$ resources from the ER. This rise of intracellular $\mathrm{Ca}^{+2}$ levels activates the protein kinase $C$ pathway, and this signal is decoded into a cellular response $[28,41,42]$.

This family of PLCs currently has 13 isozymes [43]. Although multiple isoforms of this family are only expressed in testis and sperm [44], the evidence for SOAF points to PLCל. Discovered in 2002, this novel, sperm-specific PLC is the smallest of the PLC family [45, 46] and sensitive to environmental $\mathrm{Ca}^{+2}$ concentrations, unlike other PLCs $[47,48]$. The dominant role of this protein has been demonstrated in several independent 
experiments, corroborating a series of features that made PLCל a great SOAF candidate, in addition to its presence in the sperm head. Injection of PLC $\zeta$ mRNA into mouse oocytes induced a fertilization-like $\mathrm{Ca}^{+2}$ oscillation profile $[45,46]$, while other isoforms, like PLCY mRNA, failed to do the same. Likewise, the depletion of PLC $\zeta$ in porcine or hamster sperm extracts had a reduced ability to initiate $\mathrm{Ca}^{+2}$ oscillations in oocytes [46]. Corroborating this, a transgenic mouse model, created via RNA interference technology, with PLCל-deficient sperm did not produce $\mathrm{Ca}^{+2}$ oscillations after sperm injection [49]. PLC $\zeta$ was found to be located in the equatorial segment and postacrosomal region by immunofluorescence and electron microscopy $[9,50,51]$, associated with the inner acrosomal membrane [52]. Human sperm contains variable amounts of PLC $\zeta$, that is why it possesses a variable ability to cause $\mathrm{Ca}^{+2}$ oscillations $[3,53]$. The expression patterns of this protein may play an important role in $\mathrm{Ca}^{+2}$ oscillations, and these functional roles might not be limited to oocyte activation $[54,55]$. The association between PLC $\zeta$ activity and male infertility has also been demonstrated by the expression of PLC $\zeta$ in human sperm heads [56].

The structure and functional domains of the SOAF may play an important role [57]. The PLCל structure consists of four EF-hand domains, a C2 domain, and a catalytic $\mathrm{X}$ and $\mathrm{Y}$ core domain. The main characteristics that differentiate PLC $\zeta$ from the other PLC isoforms are the EF3 zone, responsible for high $\mathrm{Ca}^{+2}$ sensitivity and the lack of a PH domain, related to the capacity of linked to G-proteins in the membranes and reacts with $\mathrm{PIP}_{2}[57$, 58] (Fig. 4a).

Despite the evidence, studies using two different knockout mouse models for PLC $\zeta$ show that male sperm can produce offspring with reduced litter size $[59,60]$. These PLCל-deficient sperm can fertilize oocytes, inducing a reduced but sufficient number of $\mathrm{Ca}^{+2}$ oscillations. The number of oscillations rises to $70 \%$ in oocytes activated by delayed pronuclei formation and increased polyspermy [60]. These results show that there is likely another unknown SOAF that can activate oocytes in the absence of PLCל. This unknown SOAF can activate oocytes when fresh sperm fertilizes oocytes in IVF, but not with the ICSI technique [61]. Nevertheless, PLCל is the main SOAF for stimulating oocyte activation in mammals. The unknown SOAF could compensate for

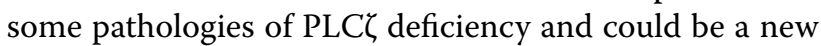
target for pharmaceutical agents, requiring further investigation. However, this unknown SOAF in the human sperm has not yet been confirmed [61, 62].

However, a SOAF candidate emerged as an alternative to PLCC: postacrosomal WW domain-binding protein (PAWP), a WBP2 $\mathrm{N}$-terminal like protein $[6,63,64]$.

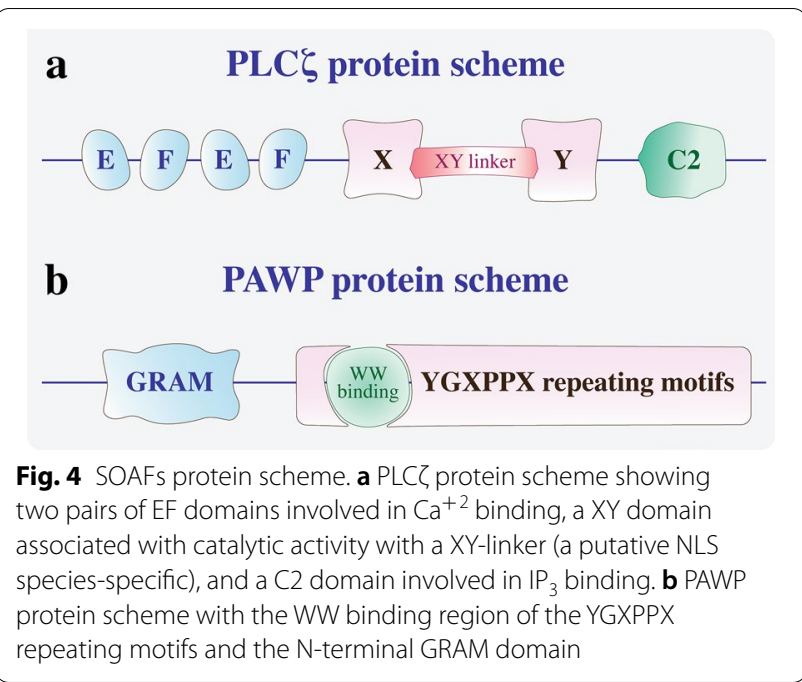

PAWP, an alkaline protein with an N-terminal WW binding domain and a C-terminal domain with a PPXY consensus binding site for group-1 WW domain-containing proteins $[6,63]$. It is located in the perinuclear matrix of the sperm head (Fig. 4b). In 2007, Wu et al. reported that PAWP promotes meiotic resumption and initiates pronuclear development during fertilization in bovine, pig, monkey, and Xenopus oocytes [6]. This finding was confirmed several years later [63] when a recombinant PAWP was injected into MII-oocytes and triggered an increase in intracellular $\mathrm{Ca}^{+2}$ levels. However, the injection of a competitive inhibitor of this protein prevented the release of intracellular $\mathrm{Ca}^{+2}$ and oscillations [65]. Other independent groups have demonstrated the association between PAWP expression and the competence of human and bull sperm $[65,66]$. However, some authors still cannot confirm a relationship between SOAF expression and $\mathrm{Ca}^{+2}$ oscillations [59, 67]. In addition, sperm from PAWP knockout mice induced normal $\mathrm{Ca}^{+2}$ oscillations in oocytes after IVF and ICSI [68].

Despite the data showing that PAWP fulfilled all the relevant requirements to be classified as a SOAF, the mechanism of PAWP inducing $\mathrm{Ca}^{+2}$ release from the ER is merely theoretical. Some authors proposed that the effects of PAWP are mediated via other proteins, like the yes-associated protein, which activates PLCY and, subsequently, the $\mathrm{IP}_{3}$ signaling pathway downstream $[6,65]$. Mehlmann et al. (1998) used an exogenous growth-factor expression to stimulate the PLCY pathway, allowing $\mathrm{Ca}^{+2}$ oscillations in mouse oocytes [27]. However, the relationship between PAWP expression, PLC $\gamma$ activity, and $\mathrm{Ca}^{+2}$ oscillations could not be demonstrated; plus, the rise of intracellular $\mathrm{Ca}^{+2}$ levels mediated by PAWP did not show wavelike characteristics, the trademark of mammalian 
fertilization [27, 67]. Conversely, no conclusive evidence shows that this PLC isozyme, PLC $\gamma$, plays a significant role in oocyte activation [27], and is not as sensitive to $\mathrm{Ca}^{+2}$ as PLCC [47].

At present, the complete molecular mechanism by which SOAF, PLCל or PAWP, activates the oocyte still remains unclear. Moreover, one of the theories proposes that PAWP activates PLC $\zeta$, and then PLC $\zeta$ hydrolyzes $\mathrm{PIP}_{2}$ [58]. However, this mechanism requires further research, Aarabi et al. (2014) suggest that the C-terminal domain of PAWP, which is rich in proline and presents a PPXY consensus sequence, interacts with a WW-group I protein domain from PLC $\zeta$, and activate it. This activation of PLCC allows the hydrolyzation of $\mathrm{PIP}_{2}$ and trigger the $\mathrm{Ca}^{+2}$ oscillations. The authors propose that when the PPXY region of PAWP is blocked, the oocyte activation failed [65].

\section{Epigenetic regulation during fertilization}

The sperm epigenome modifications include DNA methylation, post-transcriptional modifications of histones, and non-coding RNAs (ncRNAs) [69]. These epigenetic events affect early embryo development, and cause phenotypic changes in the offspring [70]. During fertilization, sperm DNA compaction and protamine replacement are the most important events to form the zygote nucleus, while ncRNAs are involved in embryonic development and transgenerational adaptation [69].

Sperm chromatin includes testicular histones, protamines, and free DNA, called nuclear matrix. The complex transition between the oocyte and the spermatozoon chromatin structure is poorly understood, but it is known that in the spermatozoon, the protamine incorporation during spermatogenesis, as well as its removal upon fecundation are, apparently, critical for paternal epigenetics profile and reprogramming. It has been demonstrated that there is non-random retention of testicular histones in a specific region of the DNA during spermatogenesis, and the more "relaxed" state of the DNA in these regions provides conditions to epigenetic marks [70-72]. In contrast to the passive demethylation that occurs in the oocyte DNA upon fertilization, the sperm chromatin undergoes throughout deprotamination followed by dramatic demethylation and active decondesation of the chromatin, creating an environment that facilitates a new methylation profile, thus new epigenetics marks, suggesting that determination of cellular fates for tissue specification is critical [73-76].

ncRNAs are involved in gene expression either by cleavage targets mRNAs or by blocking mRNAs translation. Although the presence of different types of ncRNAs in the sperm has been demonstrated, the function of these during fertilization is not clear [69].

\section{Oocyte activation failures}

After fusion of the sperm with the oocyte membrane, pronucleus formation occurs. Lack of pronuclei is a clear sign of failed fertilization during ICSI. The mechanism through which the human oocyte is activated during ICSI is different from natural fertilization, yet approximately $85 \%$ of attempts successfully lead to pregnancy. However, a percentage of ICSI cycle failure has been reported [77], even with good ovarian response and semen quality. As the spermatozoon is already within the oocyte, the fertilization failure could be associated with sperm factors or oocyte activation machinery. Failed fertilization after ICSI may be attributable to the lack of $\mathrm{Ca}^{+2}$ oscillations, both related to total or partial oocyte fertilization [61].

TFF occurs when all the oocytes collected within one cycle of stimulation fail to form pronuclei after ICSI; OAD is the main cause of TFF in recurrent ICSI failure [78-80]. Between 1 and 5\% of ICSI cycles repeatedly fail, associated with abortive oocyte activation [8, 81-83]. Numerous reports have shown that sperm factors affect oocyte activation, specifically the lack of PLC $\zeta$ or mutation in PLC $\zeta$ in the sperm $[50,84]$. The absence

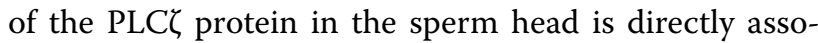
ciated with the failure to produce $\mathrm{Ca}^{+2}$ oscillations [8, 84]; therefore, an effective way to determine the cause of ICSI failure is to inject human sperm into mouse oocytes and observe the spermatozoon's ability to trigger $\mathrm{Ca}^{+2}$ oscillations. Other causes of OAD are mutations in the

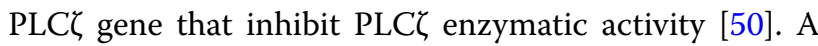
notable example is the case of two brothers with homozygous mutations in the $\mathrm{C}$ domain of PLC $\zeta$; this mutation reduced the PLC $\zeta$ expression in the sperm and disrupted activity [85]. These findings strongly suggest that this mutation can cause male infertility in humans.

Another genetic pathology known as globozoospermia is associated with the capability of activating oocytes. This autosomal-recessive pathology, which can be partial or total, is commonly caused by mutations in the DPY19L2 gene involved in developing the acrosome and elongation of the sperm head; therefore, the spermatozoon lacks the acrosome or shows an abnormality in other structures that provide its characteristic shape [8, 50]. Many cases of globozoospermia are associated with a lack of PLCC [52]. Less common causes of TFF are sperm head decondensation, premature sperm chromatin condensation, oocyte spindle defects, and sperm defects [86].

The type of failed fertilization related to oocyte activation after an ICSI cycle is associated with the low ability of the sperm to stimulate $\mathrm{Ca}^{+2}$ oscillations [61]. FerrerBuitrago et al. (2018) found that $30 \%$ of control sperm from fertile men could not effectively prolong $\mathrm{Ca}^{+2}$ signaling in human oocytes [87]. This report is consistent with the immunostaining results of sperm from fertile 
men, which showed a variable localization and amount of PLC [3].

\section{Current situation of diagnosis and treatment for oocyte activation failure}

ARTs involve ovarian stimulation, gamete and embryo manipulation, and cryopreservation. At present, IVF and ICSI are reproductive technologies that are widely used to treat infertility related to reproductive endocrinology, genetic disorders, oocyte donation, and surrogacy. The aim of ART is to attain a successful pregnancy, and during this process, most biological barriers are bypassed, especially when ICSI is applied, because a morphologically normal spermatozoon is directly injected into a mature oocyte [7]. Since the early 1990s, when the first pregnancy using ICSI was reported [88], almost any type of spermatozoa were used to fertilize an oocyte. Today, the clinical situation has improved with research, allowing the investigation and determination of gene expression, proteins, and molecular pathways related to gamete formation and development, fertilization processes, and embryo development.

The lack of pronuclei formation after a conventional IVF procedure is a clear sign of fertilization failure. The reasons can be multiple, such as non-recognition between the spermatozoon and the oocyte or failure of acrosome reaction, among others. Currently, ICSI is the preferred treatment when conventional IVF fails. Applied, for example, when oocytes are cryopreserved or in severe male infertility cases. Although there is controversy, there are two main sources of potentially usable sperm, testicular or epididymal spermatozoa obtained through biopsies or ejaculated sperm. While the protamine content in the ejaculated spermatozoa confers the ability to be reprogrammed after fertilization [89], thus the ejaculated sperm is thought to be more mature; it has been proposed that the extraction of testicular sperm may eliminate the exposure to the reactive oxygen species and could result in the access to high-quality spermatozoa [90].

According to the Human Fertilization and Embryology Authority, the leading cause for ICSI treatment in about $50 \%$ of the cases [91] is related to the male factor. However, most cases are successful, but there is a small percentage of cases in which conventional ICSI fails. The mechanisms that are altered are unknown, and researchers are currently uncertain of solutions. In most cases, other complementary strategies, such as chemical adjuvants or alternative techniques, are applied to improve fertilization and achieve better embryo development.

As previously discussed, OAD is the most common cause of ICSI cycle failure. Oocyte activation is a complex and not completely known sequence of molecular events that includes gamete membrane fusion, exocytosis of cortical granules of the oocyte, oocyte intracellular $\mathrm{Ca}^{+2}$ release and oscillations, recruitment of maternal mRNA, pronucleus formation, and polyspermy prevention. Localization patterns of proteins, receptors, DNA, and membrane integrity help elucidate the stages in oocyte activation and reasons for failures; they also help to develop diagnostic tests and therapeutic strategies to restore fertilization, either through pharmaceutical agents or reproductive technology or both.

Increasing evidence shows that PLCK is the most important SOAF. It activates $\mathrm{Ca}^{+2}$ oscillations through $\mathrm{PIP}_{2}$ hydrolysis to $\mathrm{IP}_{3}$ and DAG. On the ER's surface, $\mathrm{IP}_{3}$ binds to its receptors and triggers $\mathrm{Ca}^{+2}$ release in a wave pattern. As previously demonstrated, OAD could be caused by abnormal patterns of distribution or reduced amounts of PLC $\zeta$, among other factors, which could lead to a failure in the release and oscillations of $\mathrm{Ca}^{+2}$ [3, 84, 92], altering the downstream pathway. In reproductive medicine, when $\mathrm{Ca}^{+2}$ oscillations fail, mainly because of the absence or diminished amount of PLC $\zeta$, the most common procedure is artificial activation of the oocytes prior to ICSI by applying AOAs (Fig. 1-artificial activation).

Artificial stimulation of oocyte activation through $\mathrm{Ca}^{+2}$ ionophores in different animals has been studied since the 1970s. Initial studies showed that the ionophore A23187 released $\mathrm{Ca}^{+2}$ from intracellular stores, and the direct injection of $\mathrm{Ca}^{+2}$ into mouse oocytes triggered the induction of parthenogenetic embryos that developed to the blastocyst stage [18]. While some authors demonstrated that human oocytes could also be activated by A23187, other groups found that A23187 and ionomycin, another ionophore similar to A23187, only cause a unique spike in $\mathrm{Ca}^{+2}$ and do not activate oocytes [93, 94]. The AOAs do not mimic the fertilization process precisely but cause a single large $\mathrm{Ca}^{+2}$ spike, which is not the natural $\mathrm{Ca}^{+2}$ oscillations $[18,94,95]$. Therefore, to activate oocytes, the most common protocol applied in humans includes the ready-to-use ionophore A23187, following ICSI $[18,96]$.

AOAs have been used for over a decade in reproductive medicine. Many reports have shown the beneficial effects of AOAs in reproductive medicine in couples with TFF $[18,97]$, male patients with severe sperm alterations including globozoospermia [98, 99], teratozoospermia [80, 100], cryptozoospermia, azoospermia [101], and sperm stress conditions, such as cryopreservation protocols [102, 103]. In 2017, Murugesu et al. reported that using a $\mathrm{Ca}^{+2}$ ionophore in ICSI treatments significantly improved oocyte activation and pregnancy rates [104]. Reports using AOAs in an ICSI cycle are contradictory, 
so it is possible that only a subset of patients will benefit from them [105].

Concern still exists regarding the potentially deleterious effects of these substances on embryogenesis [106]. Vanden Meerschaut et al. conducted a study on neonatal and neurodevelopmental outcomes in 21 children born after an ICSI-AOA treatment [107]. This group reported no severe effects in the offspring. However, the high response rate and the robustness of the test used in this study are still considered preliminary because the sample size was small.

An alternative treatment for OAD is microinjections of PLC $\zeta$ protein or as a recombinant protein (Fig. 1artificial activation). It has been demonstrated that both

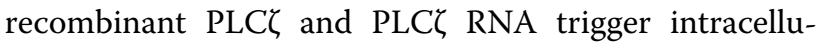
lar $\mathrm{Ca}^{+2}$ oscillations in both mouse and human oocytes $[9,103,108-110]$. The technical problem of PLC $\zeta$ RNA injections is the variable expression between oocytes, it is known that exist species-specific $\mathrm{Ca}^{+2}$ oscillatory patters, and the type of patter affects preimplantation embryonic development [14]. However, the exact mechanism is still unclear; in some species, such as mice or pigs, the $\mathrm{Ca}^{+2}$ oscillatory pattern dependent on the nuclear localization signal sequence of PLC $\zeta$ [111]. Thus, injection of PLC $\zeta$ may be useful for the activation of round spermatidinjected and somatic nuclear-transferred oocytes, but the overexpression could lead to the cleavage-stage arrest of the oocyte $[14,111,112]$, so this treatment is problematic and difficult to apply in reproductive medicine. Another important problem is the introduction of genetic material into the oocyte, which is forbidden for human medicine in most parts of the world. In contrast, recombinant PLC $\zeta$ could by synthesized in bacteria as a fusion protein. This resolves the problem of varying PLC $\zeta$ expression but gives rise to PLC $\zeta$ diminishing its activity quickly. Therefore, recombinant PLC $\zeta$ protein must be stabilized and calibrated before its application [61]. Still, its application in IVF clinics is limited because of commercial availability.

As an alternative, there are treatments with external agents, including pharmacological, chemical, or microinjection with PLC $\zeta$. Authors have proposed that routine sperm preparation methods, including density gradient selection or swim-up (selecting sperm by motility and morphology), be modified and include other selected molecular or cellular sperm characteristics. One example is selecting for surface markers using magnetically activated cell sorting (MACS) for the selection of apoptotic sperm, which express phosphatidylserine in their membrane [113]. These modifications of preparation methods could improve sperm selection and improve fertilization treatments. Thus, Chan et al. suggested a method based on zeta-potential selection according to the electric charge that could produce a higher percentage of normal sperm morphology with intact chromatin [114]. In accordance, Khakpour et al. suggested a noninvasive method based on zeta potential, along with the densitygradient selection method, which improved the intact chromatin and membrane selection of a morphologically normal spermatozoon, with a high amount of PLC $\zeta$, important characteristics required for fertilization and oocyte activation [77].

Another strategy, proposed by authors, is a simple protocol involving the incubation of the oocytes for several minutes in media containing Strontium $\left(\mathrm{Sr}^{+2}\right)$ [115]. Although this strategy produces $\mathrm{Ca}^{+2}$ oscillation in mouse [116] and bovine [117] oocytes, in reproductive medicine, this protocol has "anecdotal clinical reports" without correct scientific methodology [61]. It has been demonstrated the presence and functionality of these channels in human oocytes, the efficiency, and the exact mechanism of $\mathrm{Sr}^{2+}$ as an oocyte activation agent in human oocytes remains largely unknown [118]. Many authors have tried to corroborate this finding in mouse oocytes but failed, with over 10 hours of incubation in $\mathrm{Sr}^{+2}$ media [61, 87, 118]. This lack of response was also observed in cows and pigs $[61,116]$. However, NoroziHafshejani et al. obtained quality embryos derived from $\mathrm{SrCl}_{2}$ activation prior to ICSI, although this treatment was less efficient than the Ca-ionophore stimulus [115].

These strategies enable solutions for infertility problems related to the spermatozoon, such as globozoospermia or recurrent ICSI cycle failure because of OAD. It must be noted that not all cases are similar, so treatment could differ among patients, and some recommendations/guidelines must be followed. The AOA treatments are only recommended in cases when PLC $\zeta$ deficiency has been observed [119]. However, when sperm preparation procedures target some characteristics of the spermatozoon, such as DNA fragmentation levels or acrosome and membrane integrity, modifications of the preparation method must be chosen with care [120].

\section{Discussion}

Since Jacques Loeb proposed that the spermatozoon plays a key role in fertilization, more than just providing genetic material [11], a new field in reproductive biology opened a series of investigations and debates on the role of the male gamete in early embryo development and its effects on the offspring. This resulted in the knowledge of spermatozoon factors as fundamental to initiating oocyte activation, and the sperm epigenome important role for successful embryogenesis.

Numerous hypotheses have been offered explaining how the sperm activates the oocyte by increasing 


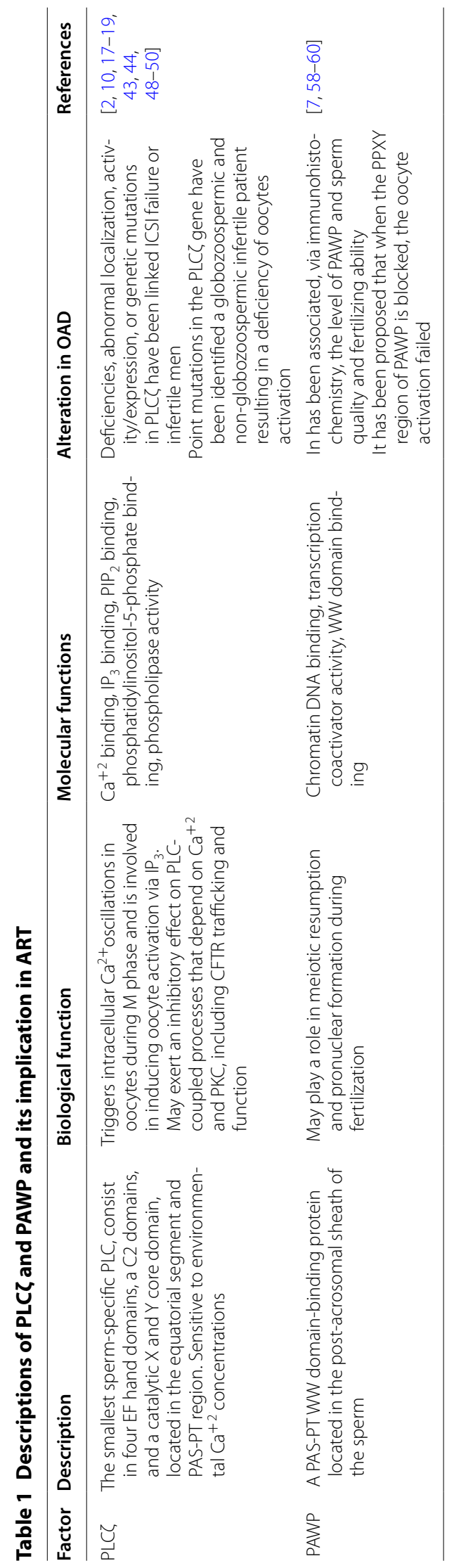


intracellular $\mathrm{Ca}^{+2}$ oscillations. Many factors and molecular pathways have been studied to determine pronuclear formation, for which the oocyte machinery modifies the sperm chromatin structure after fertilization.

Several mammals, as well as heterologous ICSI, have been used as model systems to study oocyte activation. Among these, similar observations between human and mouse oocyte fertilization and activation mechanism and embryo development processes allow us to compare and contrast the details $[9,84,92,112,121-124]$. The development of ART, especially ICSI techniques that bypass any oocyte-sperm membrane-binding mechanism, concluded with a soluble SOAF that enters the oocyte upon fertilization, surviving to the acrosome reaction.

The discovery of PLCY and the demonstrations of its role as a SOAF is vital [14], plus another potential candidate is under investigation, PAWP (Table 1). However, while both meet the requirements proposed, sperm location and ability to trigger $\mathrm{Ca}^{+2}$ oscillations signals, at present, do not explain how PAWP triggers intracellular $\mathrm{Ca}^{+2}$ release; therefore, its mechanism remains theoretical [125].

Since all IVF clinics do not have access to animals for assays, particularly mouse models to evaluate heterologous ICSI and the ability of the human sperm to activate mouse oocytes, a standardized protocol should be developed. This protocol must have all necessary biochemical characteristics, including analytical and biological limits, a scientific validation, reference values or range, normal variation, and a consensus of the professional community when alterations are observed [126]. Evaluating PLC $\zeta$ and PAWP expression in infertile men with previous fertilization failure by immunostaining showed that both proteins were under expressed in patient sperm. However, the authors proposed that both proteins are SOAF candidates and could be diagnostic markers; the findings are ambiguous since a lack of common diagnosis protocols can determine PLC $\zeta$ activity or PAWP. Thus, treatments are empirical since not all patients respond to AOA treatments and each IVF clinic has its own protocol for such cases.

Alterations in gamete development or the fertilization process show that embryogenesis may fail or that multiple disorders could appear in offspring. In human reproduction, maternal, paternal, or idiopathic factors could cause this. Therefore, new advances in biotechnology have informed reproductive medicine to manage these pathologies. The use of ARTs in human infertility cases, such as ICSI and preimplantation genetic diagnosis or screening (PGD or PGS), has been enormously useful for morphologically and genetically normal embryo transfer, plus the study of fertility failures. In the future, additional factors or mechanisms associated with oocyte maturation must be studied. It would be misguided to assume that only a single sperm factor activates oocytes. In the same way, other functions of these SOAF must be studied; for example, there is evidence that PLC $\zeta$ has a potential role in embryonic development, particularly during the early embryonic division $[20,127]$.

The role and importance of both sperm factors, PLC $\zeta$ and PAWP, among others oocytes factors and proteins, such as CAMK-II or other protein kinases, must be continuously studied to expand our knowledge and improve diagnosis and clinical treatments for infertility.

\section{Conclusions}

Through those years, the role of the spermatozoon during fertilization and beyond has become important. It is known that the sperm has an inactive role during oocyte activation, dues several sperm factors were associated with this. However, PLC $\zeta$ has been demonstrated to be the main SOAF; with an uncountable number of scientific data, it seems no to be the only one. In recent years, other candidates have risen, and this is the case of PAWP. Although the mechanism by which PAWP could activate the oocytes is not clear, many authors defend it as a SOAF. Many biological pathways are ambiguous; this may represent an alternative in the case that the main pathway is altered.

It is worth pointing out that SOAF identification and mechanism were important to study and treat male infertility, such as male cause of OAD. Nowadays, it is known that the deficiency of PLC $\zeta$ in a sperm sample could lead to a fertilization failure. However, no diagnostic test has been developed to establish the amount of PLC $\zeta$, as well as a standard protocol to deal with this type of pathologies.

\section{Abbreviations}

AOAs: Artificial oocyte activators; AOD: Oocyte activation deficiency; ART : Assisted reproductive technology; $\mathrm{Ca}^{+2}$ : Intracellular calcium; CADP ribose: Cyclic ADP-ribose; CAMK-II: Calmodulin-dependent protein kinase II; CDK-1: Cyclin-dependent kinase 1; CFTR: Cystic fibrosis transmembrane conductance regulator; CGMP: Cyclic GMP; CIRC: $\mathrm{Ca}^{+2}$-induced $\mathrm{Ca}^{+2}$ release; DAG: Diacylglycerol; DNA: Deoxyribonucleic acid; ER: Endoplasmic reticulum; GPI: Glucosamine-6-phosphate isomerase; ICSI: Intracytoplasmic sperm injection; IVF: In vitro fertilization; $I_{3}$ : Inositol-1,4,5- triphosphate; IP $_{3} R$ : Inositol-1,4,5triphosphate receptors; MACS: Magnetically activated cell sorting; MAP-kinase: Mitogen-activated protein kinase; NADP: Nicotinic acid adenine dinucleotide phosphate; ncRNAs: Non-coding RNAs; NLS: Nuclear localization signal; NO: Nitric oxide; OAD: Oocyte activation deficiency; PAS-PT: Postacrosomal sheath-perinuclear theca; PAWP: Postacrosomal WW domain-binding protein; PGD: Preimplantation genetic diagnosis; PGS: Preimplantation genetic screening; PIP $_{2}$ : Phosphatidylinositol 4,5-biphosphate; PKC: Protein kinase C; PLC: Phospholipase; PLCY: Phospholipase gamma; PLCZ: Phospholipase C zeta 1; PT: Perinuclear theca; RNA: Ribonucleic acid; RYR: Ryanodine receptors; SOAF: Sperm oocyte-activator factor; $\mathrm{Sr}^{+2}$ : Strontium; TFF: Total fertilization failure; Tr-Kit: c-kit tyrosine kinase.

\section{Acknowledgements}

None. 


\section{Authors' contributions}

MIZ and HGL conceived the concept for the review article. MIZ did the literature search, wrote the entire manuscript, revised, edited, and finalized it. $\mathrm{SL}$ and HGL contributed to writing different parts of the manuscript. HGL performed the critical review and revision of the intellectual concept and content of the article. All authors read and approved the final manuscript.

\section{Funding}

The current study was supported by the Post-doctoral Science Foundation Fund, P.R. China (2019M662636), and the Natural Science Foundation of Hubei Province, P.R. China (2017CFB780).

\section{Availability of data and materials}

Not applicable.

\section{Ethics approval and consent to participate}

Not applicable.

\section{Consent for publication}

Not applicable.

\section{Competing interests}

The authors have no conflict of interest to declare.

\section{Author details \\ ${ }^{1}$ Institute of Reproductive Health/Center of Reproductive Medicine, Tongji Medical College, Huazhong University of Science and Technology, 13 Hang Kong Road, Wuhan 430030, People's Republic of China. ${ }^{2}$ Depart- ment of Obstetrics and Gynecology, Union Hospital, Tongji Medical College, Huazhong University of Science and Technology, 1277 Jeifang Avenue, Wuhan 430022, People's Republic of China. ${ }^{3}$ Wuhan Tongji Reproductive Medicine Hospital, 128 Sanyang Road, Wuhan 430013, People's Republic of China.}

Received: 21 October 2020 Accepted: 15 December 2020

Published online: 06 January 2021

\section{References}

1. Shirakawa H, Kikuchi T, Ito M. Calcium signaling in mammalian eggs at fertilization. Curr Top Med Chem. 2016;16:2664-76.

2. Nomikos M, Kashir J, Swann K, Lai FA. Sperm PLCC: from structure to Ca2 + oscillations, egg activation and therapeutic potential. FEBS Lett. 2013;587:3609-16.

3. Kashir J, Jones C, Mounce G, Ramadan WM, Lemmon B, Heindryckx B, et al. Variance in total levels of phospholipase $C$ zeta (PLC- $\zeta$ ) in human sperm may limit the applicability of quantitative immunofluorescent analysis as a diagnostic indicator of oocyte activation capability. Fertil Steril. 2013:99:107-17.

4. Ostermeier GC, Miller D, Huntriss JD, Diamond MP, Krawetz SA. Reproductive biology: delivering spermatozoan RNA to the oocyte. Nature. 2004:429:154.

5. Gòdia M, Swanson G, Krawetz SA. A history of why fathers'RNA matters. Biol Reprod. 2018:99:147-59.

6. Wu ATH, Sutovsky P, Manandhar G, Xu W, Katayama M, Day BN, et al. PAWP, a sperm-specific WW domain-binding protein, promotes meiotic resumption and pronuclear development during fertilization. J Biol Chem. 2007;282:12164-75.

7. Palermo GD, Neri QV, Schlegel PN, Rosenwaks Z. Intracytoplasmic Sperm Injection (ICSI) in extreme cases of male infertility. PLoS ONE. 2014;9:e113671.

8. Vanden Meerschaut F, Nikiforaki D, Heindryckx B, De Sutter P. Assisted oocyte activation following ICSI fertilization failure. Reprod Biomed Online. 2014;28:560-71.

9. Yoon S-Y, Eum JH, Lee JE, Lee HC, Kim YS, Han JE, et al. Recombinant human phospholipase C zeta 1 induces intracellular calcium oscillations and oocyte activation in mouse and human oocytes. Hum Reprod. 2012;27:1768-80.
10. Jenkins TG, Aston KI, James ER, Carrell DT. Sperm epigenetics in the study of male fertility, offspring health, and potential clinical applications. Syst Biol Reprod Med. 2017;63:69-76.

11. Loeb J. Artificial parthenogenesis and fertilization. Chicago: Univ Chicago Press; 1913.

12. Ohto U, Ishida H, Krayukhina E, Uchiyama S, Inoue N, Shimizu T. Structure of IZUMO1-JUNO reveals sperm-oocyte recognition during mammalian fertilization. Nature. 2016;534:566-9.

13. Miyazaki S, Ito M. Calcium signals for egg activation in mammals. J Pharmacol Sci. 2006;100:545-52.

14. Parrington J, Arnoult C, Fissore RA. The eggstraordinary story of how life begins. Mol Reprod Dev. 2019;86:4-19.

15. Swann K, Lai FA. PLC and the initiation of $\mathrm{Ca}(2+)$ oscillations in fertilizing mammalian eggs. Cell Calcium. 2013;53:55-62.

16. Machaty $Z$. Signal transduction in mammalian oocytes during fertilization. Cell Tissue Res. 2016;363:169-83.

17. Machaty Z, Miller AR, Zhang L. Egg activation at fertilization. Adv Exp Med Biol. 2017:953:1-47.

18. Anifandis G, Michopoulos A, Daponte A, Chatzimeletiou K, Simopoulou M, Messini Cl, et al. Artificial oocyte activation: physiological, pathophysiological and ethical aspects. Syst Biol Reprod Med. 2019:65:3-11.

19. Wakai T, Zhang N, Vangheluwe P, Fissore RA. Regulation of endoplasmic reticulum $\mathrm{Ca}(2+)$ oscillations in mammalian eggs. J Cell Sci. 2013;126:5714-24.

20. Ozil J-P, Banrezes B, Tóth S, Pan H, Schultz RM. Ca2 + oscillatory pattern in fertilized mouse eggs affects gene expression and development to term. Dev Biol. 2006;300:534-44.

21. Levasseur MD, Thomas C, Davies OR, Higgins JMG, Madgwick S. Aneuploidy in oocytes is prevented by sustained CDK1 activity through degron masking in cyclin B1. Dev Cell. 2019:48:672-84.e5.

22. Jones KT. Mammalian egg activation: from Ca2 + spiking to cell cycle progression. Reproduction. 2005;130:813-23.

23. Tosti E, Ménézo Y. Gamete activation: basic knowledge and clinical applications. Hum Reprod Update. 2016:22:420-39.

24. Machaty Z, Wang C, Lee K, Zhang L. Fertility: Store-operated Ca2+ entry in germ cells: role in egg activation. Adv Exp Med Biol. 2017:993:577-93.

25. Jaffe LA. First messengers at fertilization. J Reprod Fertil Suppl. 1990:42:107-16.

26. Williams CJ, Mehlmann LM, Jaffe LA, Kopf GS, Schultz RM. Evidence that $\mathrm{Gq}$ family $\mathrm{G}$ proteins do not function in mouse egg activation at fertilization. Dev Biol. 1998;198:116-27.

27. Mehlmann LM, Carpenter G, Rhee SG, Jaffe LA. SH2 domain-mediated activation of phospholipase Cgamma is not required to initiate Ca2 + release at fertilization of mouse eggs. Dev Biol. 1998;203:221-32.

28. Swann K. A cytosolic sperm factor stimulates repetitive calcium increases and mimics fertilization in hamster eggs. Development. 1990;110:1295-302.

29. Oko R, Sutovsky P. Biogenesis of sperm perinuclear theca and its role in sperm functional competence and fertilization. J Reprod Immunol. 2009;83:2-7.

30. Toshimori $\mathrm{K}$, Ito C. Formation and organization of the mammalian sperm head. Arch Histol Cytol. 2003;66:383-96.

31. Kimura Y, Yanagimachi R, Kuretake S, Bortkiewicz H, Perry AC, Yanagimachi $\mathrm{H}$. Analysis of mouse oocyte activation suggests the involvement of sperm perinuclear material. Biol Reprod. 1998;58:1407-15.

32. $\mathrm{Wu} \mathrm{H}, \mathrm{He} \mathrm{CL}$, Fissore RA. Injection of a porcine sperm factor triggers calcium oscillations in mouse oocytes and bovine eggs. Mol Reprod Dev. 1997:46:176-89.

33. Parrington J, Lai FA, Swann K. A novel protein for Ca2 + signaling at fertilization. Curr Top Dev Biol. 1998;39:215-43.

34. Wolosker H, Kline D, Bian Y, Blackshaw S, Cameron AM, Fralich TJ, et al Molecularly cloned mammalian glucosamine-6-phosphate deaminase localizes to transporting epithelium and lacks oscillin activity. FASEB J. 1998;12:91-9.

35. Wolny YM, Fissore RA, Wu H, Reis MM, Colombero LT, Ergün B, et al. Human glucosamine-6-phosphate isomerase, a homologue of hamster oscillin, does not appear to be involved in Ca2 + release in mammalian oocytes. Mol Reprod Dev. 1999;52:277-87. 
36. Harada Y, Matsumoto T, Hirahara S, Nakashima A, Ueno S, Oda S, et al. Characterization of a sperm factor for egg activation at fertilization of the newt Cynops pyrrhogaster. Dev Biol. 2007;306:797-808.

37. Haghighat S, Tavalaee M, Zakeri Z, Noureddini M, Shahverdi A, Nasr Esfahani MH. Reduction of truncated kit expression in men with abnormal semen parameters, globozoospermia and history of low or fertilization failure. Cell J. 2019:21:314-21

38. Muciaccia B, Sette C, Paronetto MP, Barchi M, Pensini S, D'Agostino A, et al. Expression of a truncated form of KIT tyrosine kinase in human spermatozoa correlates with sperm DNA integrity. Hum Reprod. 2010;25:2188-202.

39. Sanders JR, Swann K. Molecular triggers of egg activation at fertilization in mammals. Reproduction. 2016;152:R41-50.

40. Jellerette $\mathrm{T}, \mathrm{He} \mathrm{CL}, \mathrm{Wu} \mathrm{H}$, Parys JB, Fissore RA. Down-regulation of the inositol 1,4,5-trisphosphate receptor in mouse eggs following fertilization or parthenogenetic activation. Dev Biol. 2000;223:238-50.

41. von Stetina JR, Orr-Weaver TL. Developmental control of oocyte maturation and egg activation in metazoan models. Cold Spring Harb Perspect Biol. 2011;3:1-19.

42. Whitaker M. Calcium at fertilization and in early development. Physiol Rev. 2006;86:25-88.

43. Kadamur G, Ross EM. Mammalian phospholipase C. Annu Rev Physiol Annu Rev. 2013;75:127-54

44. Parrington J, Jones ML, Tunwell R, Devader C, Katan M, Swann K. Phospholipase $\mathrm{C}$ isoforms in mammalian spermatozoa: potential components of the sperm factor that causes $\mathrm{Ca} 2+$ release in eggs. Reproduction. 2002;123:31-9.

45. Cox LJ, Larman MG, Saunders CM, Hashimoto K, Swann K, Lai FA. Sperm phospholipase $\mathrm{C \zeta}$ from humans and cynomolgus monkeys triggers Ca2+ oscillations, activation and development of mouse oocytes Reproduction. 2002:124:611-23.

46. Saunders CM, Larman MG, Parrington J, Cox LJ, Royse J, Blayney LM, et al. PLCC: A sperm-specific trigger of $\mathrm{Ca} 2+$ oscillations in eggs and embryo development. Development. 2002;129:3533-44.

47. Rice A, Parrington J, Jones KT, Swann K. Mammalian sperm contain a $\mathrm{Ca}(2+)$-sensitive phospholipase $\mathrm{C}$ activity that can generate InsP(3) from PIP(2) associated with intracellular organelles. Dev Biol. 2000;228:125-35.

48. Jones KT, Matsuda M, Parrington J, Katan M, Swann K. Different Ca2+releasing abilities of sperm extracts compared with tissue extracts and phospholipase $\mathrm{C}$ isoforms in sea urchin egg homogenate and mouse eggs. Biochem J. 2000;346:743-9.

49. Knott JG, Kurokawa M, Fissore RA, Schultz RM, Williams CJ. Transgenic RNA interference reveals role for mouse sperm phospholipase Czeta in triggering $\mathrm{Ca} 2+$ oscillations during fertilization. Biol Reprod. 2005;72:992-6.

50. Kashir J, Heindryckx B, Jones C, de Sutter P, Parrington J, Coward K. Oocyte activation, phospholipase C zeta and human infertility. Hum Reprod Update. 2010;16:690-703.

51. Swann K, Saunders CM, Rogers NT, Lai FA. PLC Ceta(zeta): a sperm protein that triggers $\mathrm{Ca} 2+$ oscillations and egg activation in mammals. Semin Cell Dev Biol. 2006;17:264-73.

52. Escoffier J, Yassine S, Lee HC, Martinez G, Delaroche J, Coutton C, et al: Subcellular localization of phospholipase $C \zeta$ in human sperm and its absence in DPY19L2-deficient sperm are consistent with its role in oocyte activation. Mol Hum Reprod. 2015;21:157-68.

53. Grasa P, Coward K, Young C, Parrington J. The pattern of localization of the putative oocyte activation factor, phospholipase Cद, in uncapacitated, capacitated, and ionophore-treated human spermatozoa. Hum Reprod. 2008:23:2513-22.

54. Aarabi M, Yu Y, Xu W, Tse MY, Pang SC, Yi Y-J, et al. The testicular and epididymal expression profile of PLCZ in mouse and human does not support its role as a sperm-borne oocyte activating factor. PLOS ONE. 2012; 7:e33496.

55. Yelumalai S, Yeste M, Jones C, Amdani SN, Kashir J, Mounce G, et al. Total levels, localization patterns, and proportions of sperm exhibiting phospholipase $C$ zeta are significantly correlated with fertilization rates after intracytoplasmic sperm injection. Fertil Steril. 2015;104(561-8):e4.

56. Young C, Grasa P, Coward K, Davis LC, Parrington J. Phospholipase C zeta undergoes dynamic changes in its pattern of localization in sperm during capacitation and the acrosome reaction. Fertil Steril. 2009;91:2230-42.

57. Nomikos M, Kashir J, Lai FA. The role and mechanism of action of sperm PLC-zeta in mammalian fertilisation. Biochem J. 2017;474:3659-73.

58. Yeste M, Jones C, Amdani SN, Patel S, Coward K. Oocyte activation deficiency: a role for an oocyte contribution? Hum Reprod. 2016;22:23-47.

59. Hachem A, Godwin J, Ruas M, Lee HC, Buitrago MF, Ardestani G, et al. $\mathrm{PLC \zeta}$ is the physiological trigger of the $\mathrm{Ca} 2+$ oscillations that induce embryogenesis in mammals but conception can occur in its absence. Dev. 2017;144:2914-24.

60. Nozawa K, Satouh Y, Fujimoto T, Oji A, Ikawa M. Sperm-borne phospholipase $C$ zeta-1 ensures monospermic fertilization in mice. Sci Rep. 2018:8:1-10.

61. Swann $\mathrm{K}$. The role of $\mathrm{Ca} 2+$ in oocyte activation during In Vitro fertilization: Insights into potential therapies for rescuing failed fertilization. Biochim Biophys Acta Mol Cell Res. 2018;1865:1830-7.

62. Swann K. The soluble sperm factor that actives egg: PLC eta and beyond. Reproduction. 2020;160:10-2.

63. Aarabi M, Qin Z, Xu W, Mewburn J, Oko R. Sperm-borne protein, PAWP, initiates zygotic development in Xenopus laevis by eliciting intracellular calcium release. Mol Reprod Dev. 2010;77:249-56.

64. Nomikos M, Swann K, Lai FA. Is PAWP the "real" sperm factor? Asian J Androl. 2015;17:444-6.

65. Aarabi M, Balakier H, Bashar S, Moskovtsev SI, Sutovsky P, Librach CL, et al. Sperm-derived WW domain-binding protein, PAWP, elicits calcium oscillations and oocyte activation in humans and mice. FASEB J. 2014:28:4434-40

66. Kennedy CE, Krieger KB, Sutovsky M, Xu W, Vargovič P, Didion BA, et al. Protein expression pattern of PAWP in bull spermatozoa is associated with sperm quality and fertility following artificial insemination. Mol Reprod Dev. 2014:81:436-49.

67. Nomikos M, Sanders JR, Theodoridou M, Kashir J, Matthews E, Nounesis $G$, et al. Sperm-specific post-acrosomal WW-domain binding protein (PAWP) does not cause Ca2+ release in mouse oocytes. Mol Hum Reprod. 2014;20:938-47.

68. Satouh Y, Nozawa K, Ikawa M. Sperm postacrosomal WW domainbinding protein is not required for mouse egg activation1. Biol Reprod. 2015:93:94.

69. Le Blévec E, Muroňová J, Ray PF, Arnoult C. Paternal epigenetics: mammalian sperm provide much more than DNA at fertilization. Mol Cell Endocrinol. 2020;518:110964.

70. Arpanahi A, Brinkworth M, Iles D, Krawetz SA, Paradowska A, Platts AE, Saida M, Steger K, Tedder PMD. Endonuclease-sensitive regions of human spermatozoal chromatin are highly enriched in promoter and CTCF binding sequences. Genome Res. 2009;19:1338-1249.

71. Hammoud SS, Nix DA, Zhang H, Purwar J, Carrell DTCB, Hammoud SS, Nix DA, Zhang H, Purwar J, Carrell DT, et al. Distinctive chromatin in human sperm packages genes for embryo development. Nature. 2009:460:473-8.

72. Shi L, Wu J. Epigenetic regulation in mammalian preimplantation embryo development. Reprod Biol Endocrinol. 2009;7:59.

73. Abdalla H, Yoshizawa Y, Hochi S. Active demethylation of paternal genome in mammalian zygotes. J Reprod Dev. 2009:55:356-60.

74. Ooi SKT, Bestor TH. The colorful history of active DNA demethylation. Cell. 2008:133:1145-8.

75. Abdalla H, Hirabayashi M, Hochi S. Demethylation dynamics of the paternal genome in pronuclear-stage bovine zygotes produced by in vitro fertilization and ooplasmic injection of freeze-thawed or freezedried spermatozoa. J Reprod Dev. 2009;55:433-9.

76. Jones LE, Zalensky OA, Zalenskaya Al. Protamine withdrawal from human sperm nuclei following heterologous ICSI into hamster oocytes. Protein Pept Lett. 2012;18:811-6.

77. Khakpour S, Sadeghi E, Tavalaee M, Bahadorani M, Nasr-Esfahani MH. Zeta method: A noninvasive method based on membrane charge for selecting spermatozoa expressing high level of phospholipaseCद. Andrologia. 2019:51:1-7.

78. Sun B, Yeh J. Calcium oscillatory patterns and oocyte activation during fertilization: a possible mechanism for total fertilization failure (TFF) in human in vitro fertilization? Reprod Sci. 2020. https://doi.org/10.1007/ s43032-020-00293-5. 
79. Rawe VY. Cytoskeletal organization defects and abortive activation in human oocytes after IVF and ICSI failure. Mol Hum Reprod. 2000;6:510-6.

80. Chansel-Debordeaux L, Dandieu S, Bechoua S, Jimenez C. Reproductive outcome in globozoospermic men: update and prospects. Andrology. 2015;3:1022-34

81. Mahutte NG, Arici A. Failed fertilization: is it predictable? Curr Opin Obstet Gynecol. 2003;15:211-8.

82. Neri QV, Lee B, Rosenwaks Z, Machaca K, Palermo GD. Understanding fertilization through intracytoplasmic sperm injection (ICSI). Cell Calcium. 2014;55:24-37.

83. Yanagida K. Complete fertilization failure in ICSI. Hum cell. 2004;17:187-93.

84. Yoon SY, Jellerette T, Salicioni AM, Hoi CL, Yoo MS, Coward K, et al. Human sperm devoid of PLC, zeta 1 fail to induce $\mathrm{Ca} 2+$ release and are unable to initiate the first step of embryo development. J Clin Invest. 2008;118:3671-81.

85. Escoffier J, Lee HC, Yassine S, Zouari R, Martinez G, Karaouzène T, et al. Homozygous mutation of PLC 1 leads to defective human oocyte activation and infertility that is not rescued by the WW-binding protein PAWP. Hum Mol Genet. 2016;25:878-91.

86. Swain JE, Pool TB. ART failure: oocyte contributions to unsuccessful fertilization. Hum Reprod Update. 2008;14:431-46.

87. Ferrer-Buitrago M, Bonte D, De Sutter P, Leybaert L, Heindryckx B. Single $\mathrm{Ca} 2+$ transients vs oscillatory Ca2 + signaling for assisted oocyte activation: Limitations and benefits. Reproduction. 2018;155:R105-19.

88. Palermo G, Joris H, Devroey P, Van Steirteghem AC. Pregnancies after intracytoplasmic injection of single spermatozoon into an oocyte. Lancet. 1992;340:17-8.

89. Teperek M, Simeone A, Gaggioli V, Miyamoto K, Allen GE, Erkek S, Kwon T, Marcotte EM, Zegerman P, Bradshaw CR, Peters AH, Gurdon JB, Jullien J. Sperm is epigenetically programmed to regulate gene transcription in embryos. Genome Res. 2016;26:1034-46.

90. Ku FY, Wu CC, Hsiao YW, Kang YN. Association of sperm source with miscarriage and take-home baby after ICSI in cryptozoospermia: a meta-analysis of testicular and ejaculated sperm. Andrology. 2018;6:882-9.

91. Human Fertilisation \& Embryology Authority 2020. https://www.hfea. gov.uk/about-us/publications/

92. Heytens E, Parrington J, Coward K, Young C, Lambrecht S, Yoon S-Y, et al. Reduced amounts and abnormal forms of phospholipase $C$ zeta (PLCZeta) in spermatozoa from infertile men. Hum Reprod. 2009;24:2417-28.

93. Balakier H, Casper RF. Experimentally induced parthenogenetic activation of human oocytes. Hum Reprod. 1993;8:740-3.

94. Rinaudo P, Massobrio M, Pepperell JR, Keefe DL, Buradgunta S Dissociation between intracellular calcium elevation and develop ment of human oocytes treated with calcium ionophore. Fertil Steril. 1997;68:1086-92.

95. Kashir J, Deguchi R, Jones C, Coward K, Stricker SA. Comparative biology of sperm factors and fertilization-induced calcium signals across the animal kingdom. Mol Reprod Dev. 2013;80:787-815.

96. Miller N, Biron-Shental T, Sukenik-Halevy R, Klement AH, Sharony R, Berkovitz A. Oocyte activation by calcium ionophore and congenital birth defects: a retrospective cohort study. Fertil Steril. 2016;106:590596.e2.

97. Sfontouris IA, Nastri CO, Lima MLS, Tahmasbpourmarzouni E, RaineFenning N, Martins WP. Artificial oocyte activation to improve reproductive outcomes in women with previous fertilization failure: a systematic review and meta-analysis of RCTs. Hum Reprod. 2015;30:1831-41.

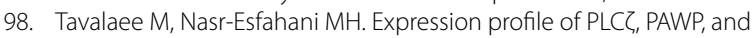
TR-KIT in association with fertilization potential, embryo development, and pregnancy outcomes in globozoospermic candidates for intracytoplasmic sperm injection and artificial oocyte activation. Andrology. 2016:4:850-6.

99. Taylor SL, Yoon SY, Morshedi MS, Lacey DR, Jellerette T, Fissore RA, et al. Complete globozoospermia associated with PLC $\zeta$ deficiency treated with calcium ionophore and ICSI results in pregnancy. Reprod Biomed Online. 2010;20:559-64.

100. Eftekhar M, Jannati S, Rahsepar M, Aflatoonian A. Effect of oocyte activation with calcium ionophore on ICSI outcomes in teratospermia: A randomized clinical trial. Int J Reprod Biomed Research Clinical Center for Infertitlity. 2013;11:875-82.

101. Ebner T, Köster M, Shebl O, Moser M, Van der Ven H, Tews G, et al. Application of a ready-to-use calcium ionophore increases rates of fertilization and pregnancy in severe male factor infertility. Fertil Steril. 2012;98:1432-7.

102. Janghorban-Laricheh E, Ghazavi-Khorasgani N, Tavalaee M, Zohrabi D, Abbasi H, Nasr-Esfahani MH. An association between sperm PLC levels and varicocele? J Assist Reprod Genet. 2016;33:1649-55.

103. Sanusi R, Yu Y, Nomikos M, Lai FA, Swann K. Rescue of failed oocyte activation after ICSI in a mouse model of male factor infertility by recombinant phospholipase Cद. Mol Hum Reprod. 2015;21:783-91.

104. Murugesu S, Saso S, Jones BP, Bracewell-Milnes T, Athanasiou T, Mania A et al. Does the use of calcium ionophore during artificial oocyte activation demonstrate an effect on pregnancy rate? A meta-analysis. Fertil Steril. 2017;108:468-82.e3.

105. Vanden Meerschaut F, Nikiforaki D, De Gheselle S, Dullaerts V, Van Den Abbeel E, Gerris J, et al. Assisted oocyte activation is not beneficial for all patients with a suspected oocyte-related activation deficiency. Hum Reprod. 2012:27:1977-84.

106. Nasr-Esfahani MH, Deemeh MR, Tavalaee M. Artificial oocyte activation and intracytoplasmic sperm injection. Fertil Steril. 2010;94:520-6.

107. Vanden Meerschaut F, D'Haeseleer E, Gysels H, Thienpont Y, Dewitte G, Heindryckx B, et al. Neonatal and neurodevelopmental outcome of children aged 3-10 years born following assisted oocyte activation. Reprod Biomed Online. 2014;28:54-63.

108. Rogers NT, Hobson E, Pickering S, Lai FA, Braude P, Swann K. Phospholipase $C \zeta$ causes Ca2 + oscillations and parthenogenetic activation of human oocytes. Reproduction. 2004;128:697-702.

109. Yamaguchi T, Ito M, Kuroda K, Takeda S, Tanaka A. The establishment of appropriate methods for egg-activation by human PLCZ1 RNA injection into human oocyte. Cell Calcium. 2017;65:22-30.

110. Nomikos M, Yu Y, Elgmati K, Theodoridou M, Campbell K, Vassilakopoulou $\mathrm{V}$, et al. Phospholipase $C \zeta$ rescues failed oocyte activation in a prototype of male factor infertility. Fertil Steril. 2013;99:76-85.

111. Yoneda A, Watanabe T. Involvement of mouse and porcine PLCZinduced calcium oscillations in preimplantation development of mouse embryos. Biochem Biophys Res Commun. 2015;460:476-81.

112. Yu Y, Saunders CM, Lai FA, Swann K. Preimplantation development of mouse oocytes activated by different levels of human phospholipase C zeta. Hum Reprod. 2008;23:365-73.

113. Stimpfel M, Verdenik I, Zorn B, Virant-Klun I. Magnetic-activated cell sorting of non-apoptotic spermatozoa improves the quality of embryos according to female age: a prospective sibling oocyte study. J Assist Reprod Genet. 2018;35:1665-74.

114. Chan PJ, Jacobson JD, Corselli JU, Patton WC. A simple zeta method for sperm selection based on membrane charge. Fertil Steril. 2006;85:481-6.

115. Norozi-Hafshejani M, Tavalaee M, Azadi L, Bahadorani M, Nasr-Esfahani $\mathrm{MH}$. Effects of assisted oocyte activation with calcium-ionophore and strontium chloride on in vitro ICSI outcomes. Iran J Basic Med Sci. 2018;21:1109-17.

116. Carvacho I, Lee HC, Fissore RA, Clapham DE. TRPV3 Channels mediate strontium-induced mouse-egg activation. Cell Rep. 2013;5:1375-86.

117. Méo SC, Yamazaki W, Leal CLV, De Oliveira JA, Garcia JM. Use of strontium for bovine oocyte activation. Theriogenology. 2005;63:2089-102.

118. LuY, Reddy R, Ferrer Buitrago M, Vander Jeught M, Neupane J, De Vos $\mathrm{WH}$, et al. Strontium fails to induce $\mathrm{Ca} 2+$ release and activation in human oocytes despite the presence of functional TRPV3 channels. Hum Reprod open. 2018;2018:hoy005.

119. Van Blerkom J, Cohen J, Johnson M. A plea for caution and more research in the "experimental" use of ionophores in ICSI. Reprod Biomed Online. 2015;30:323-4.

120. Rappa KL, Rodriguez HF, Hakkarainen GC, Anchan RM, Mutter GL, Asghar W. Sperm processing for advanced reproductive technologies: Where are we today? Biotechnol Adv. 2016;34:578-87.

121. Araki Y, Yoshizawa M, Abe H, Murase Y, Araki Y. Use of mouse oocytes to evaluate the ability of human sperm to activate oocytes after failure of activation by intracytoplasmic sperm injection. Zygote. 2004;12:111-6.

122. Vanden Meerschaut F, Leybaert L, Nikiforaki D, Qian C, Heindryckx B, De Sutter P. Diagnostic and prognostic value of calcium oscillatory 
pattern analysis for patients with ICSI fertilization failure. Hum Reprod. 2013:28:87-98.

123. Nikiforaki D, Vanden Meerschaut F, De Gheselle S, Qian C, Van den Abbeel E, De Vos WH, et al. Sperm involved in recurrent partial hydatidiform moles cannot induce the normal pattern of calcium oscillations. Fertil Steril. 2014;102:581-8.e1.

124. Kashir J, Jones C, Lee HC, Rietdorf K, Nikiforaki D, Durrans C, et al. Loss of activity mutations in phospholipase C zeta (PLCZ) abolishes calcium oscillatory ability of human recombinant protein in mouse oocytes. Hum Reprod. 2011;26:3372-87.

125. Amdani SN, Yeste M, Jones C, Coward K. Sperm factors and oocyte activation: current controversies and considerations1. Biol Reprod. 2015:93:50-1.
126. Azad N, Nazarian H, Nazari L, Novin MG, Piryaei A, Heidari MH, et al. Evaluation of PAWP and PLCZ expression in infertile men with previous ICSI fertilization failure. Urol J. 2017;15:38-43.

127. Saleh A, Kashir J, Thanassoulas A, Safieh-Garabedian B, Lai FA, Nomikos M. Essential role of sperm-specific PLC-zeta in egg activation and male factor infertility: an update. Front Cell Dev Biol. 2020;8:28.

\section{Publisher's Note}

Springer Nature remains neutral with regard to jurisdictional claims in published maps and institutional affiliations.
Ready to submit your research? Choose BMC and benefit from:

- fast, convenient online submission

- thorough peer review by experienced researchers in your field

- rapid publication on acceptance

- support for research data, including large and complex data types

- gold Open Access which fosters wider collaboration and increased citations

- maximum visibility for your research: over 100M website views per year

At BMC, research is always in progress.

Learn more biomedcentral.com/submissions 